\title{
Can We Use the Intrinsic Left Ventricular Delay (QLV) to Optimize the Pacing Configuration for Cardiac Resynchronization Therapy With a Quadripolar Left Ventricular Lead?
}

Citation for published version (APA):

van Everdingen, W. M., Zweerink, A., Cramer, M. J., Doevendans, P. A., Nguyen, C., van Rossum, A. C., Prinzen, F. W., Vernooy, K., Allaart, C. P., \& Meine, M. (2018). Can We Use the Intrinsic Left Ventricular Delay (QLV) to Optimize the Pacing Configuration for Cardiac Resynchronization Therapy With a Quadripolar Left Ventricular Lead? Circulation-Arrhythmia and Electrophysiology, 11(3), [005912]. https://doi.org/10.1161/CIRCEP.117.005912

Document status and date:

Published: 01/03/2018

DOI:

10.1161/CIRCEP.117.005912

Document Version:

Publisher's PDF, also known as Version of record

\section{Document license:}

Taverne

\section{Please check the document version of this publication:}

- A submitted manuscript is the version of the article upon submission and before peer-review. There can be important differences between the submitted version and the official published version of record. People interested in the research are advised to contact the author for the final version of the publication, or visit the DOI to the publisher's website.

- The final author version and the galley proof are versions of the publication after peer review.

- The final published version features the final layout of the paper including the volume, issue and page numbers.

Link to publication

\footnotetext{
General rights rights.

- You may freely distribute the URL identifying the publication in the public portal. please follow below link for the End User Agreement:

www.umlib.nl/taverne-license

Take down policy

If you believe that this document breaches copyright please contact us at:

repository@maastrichtuniversity.nl

providing details and we will investigate your claim.
}

Copyright and moral rights for the publications made accessible in the public portal are retained by the authors and/or other copyright owners and it is a condition of accessing publications that users recognise and abide by the legal requirements associated with these

- Users may download and print one copy of any publication from the public portal for the purpose of private study or research.

- You may not further distribute the material or use it for any profit-making activity or commercial gain

If the publication is distributed under the terms of Article 25fa of the Dutch Copyright Act, indicated by the "Taverne" license above, 


\section{Can We Use the Intrinsic Left Ventricular Delay (QLV) to Optimize the Pacing Configuration for Cardiac Resynchronization Therapy With a Quadripolar Left Ventricular Lead?}

BACKGROUND: Previous studies indicated the importance of the intrinsic left ventricular (LV) electric delay (QLV) for optimal benefit to cardiac resynchronization therapy. We investigated the use of QLV for achieving optimal acute hemodynamic response to cardiac resynchronization therapy with a quadripolar LV lead.

METHODS AND RESULTS: Forty-eight heart failure patients with a left bundle branch block were prospectively enrolled (31 men; age, $66 \pm 10$ years; LV ejection fraction, $28 \pm 8 \%$; QRS duration, 176 $\pm 14 \mathrm{~ms}$ ). Immediately after cardiac resynchronization therapy implantation, invasive LV pressure-volume loops were recorded during biventricular pacing with each separate electrode at 4 atrioventricular delays. Acute cardiac resynchronization therapy response, measured as change in stroke work $(\Delta \% \mathrm{SW})$ compared with intrinsic conduction, was related to intrinsic interval between Q on the ECG and LV sensing delay (QLV), normalized for QRS duration (QLV/QRSd), and electrode position. QLV/QRSd was $84 \pm 9 \%$ and variation between the 4 electrodes $9 \pm 5 \%$. $\Delta \%$ SW was $89 \pm 64 \%$ and varied by $39 \pm 36 \%$ between the electrodes. In univariate analysis, an anterolateral or lateral electrode position and a high QLV/ QRSd had a significant association with a large $\Delta \%$ SW (all $P<0.01$ ). In a combined model, only QLV/QRSd remained significantly associated with $\triangle \%$ SW $(P<0.05)$. However, a direct relation between QLV/QRSd and $\triangle \%$ SW was only seen in 24 patients, whereas 24 patients showed an inverse relation.

CONCLUSIONS: The large variation in acute hemodynamic response indicates that the choice of the stimulated electrode on a quadripolar lead is important. Although QLV/QRSd was associated with acute hemodynamic response at group level, it cannot be used to select the optimal electrode in the individual patient.
Wouter M. van Everdingen, $\mathrm{MD}, \mathrm{PhD}$ *

Alwin Zweerink, MD*

Maarten J. Cramer, MD, $\mathrm{PhD}$

Pieter A. Doevendans, MD, PhD

Uyên Châu Nguyên, MD, MSc

Albert C. van Rossum, MD, PhD

Frits W. Prinzen, PhD

Kevin Vernooy, MD, PhD

Cornelis P. Allaart, MD, PhD

Mathias Meine, MD, PhD 


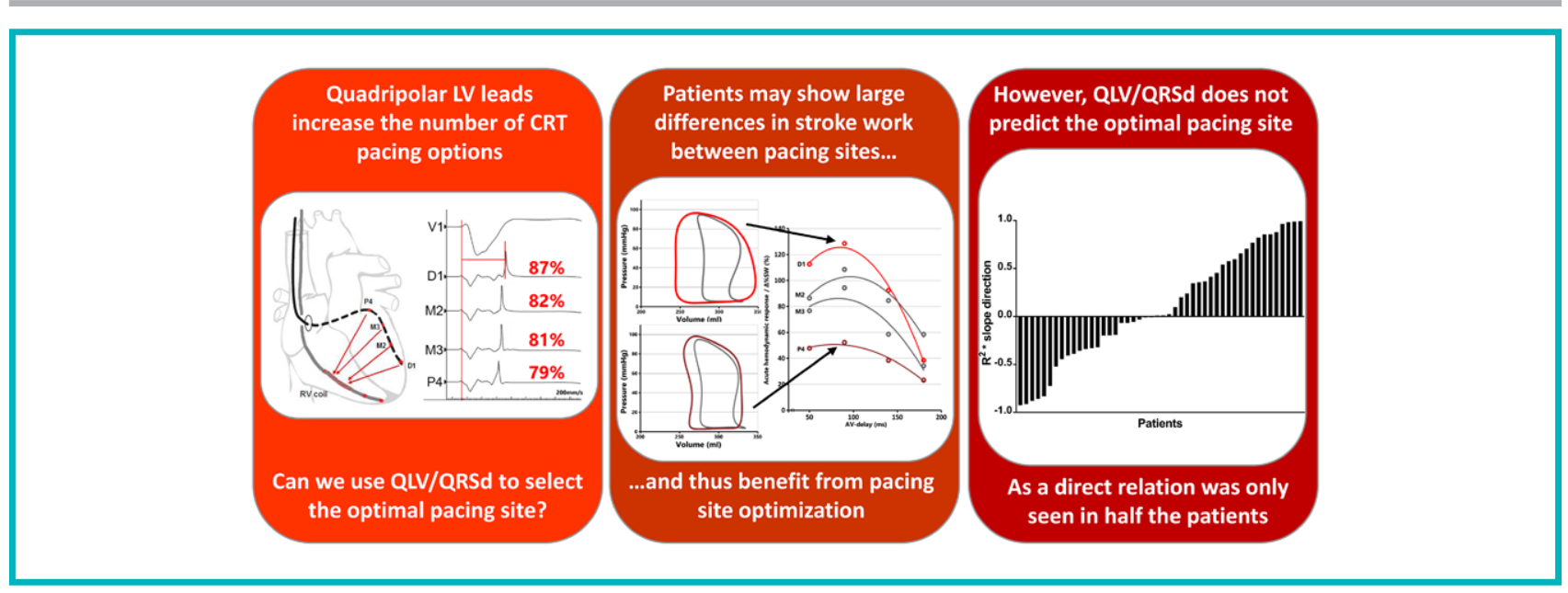

\section{WHAT IS KNOWN?}

- Optimization of cardiac resynchronization therapy (CRT) with quadripolar left ventricular (LV) leads may improve acute hemodynamic response.

- The ratio of the Q to LV sensing delay to QRS duration (QLV/QRSd) at the LV lead is a noninvasive marker that may predict acute hemodynamic response to CRT.

- LV lead position may influence response to CRT, with favorable results for lateral and nonapical leads.

\section{WHAT THE STUDY ADDS?}

- CRT candidates may benefit from optimization of the specific electrode of a quadripolar LV lead because there are large intraindividual variations in acute hemodynamic CRT response between electrodes.

- Although QLV/QRSd is associated with hemodynamic response, it does not predict the quadripolar lead electrode with the largest hemodynamic response.

- QLV/QRSd may be used to select a target vein for quadripolar LV lead placement, after which optimization should be dependent on functional assessment of CRT response.

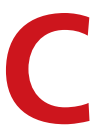
ardiac resynchronization therapy (CRT) is a proven therapy for patients with heart failure and left ventricular (LV) conduction disorder, according to most recent international guidelines. ${ }^{1}$ CRT improves prognosis, reduces mortality and morbidity, and induces reverse remodeling through electromechanical resynchronization. 2,3 Unfortunately, a substantial number of eligible patients (ie, around 30\%-40\%) show no significant response to CRT. ${ }^{4}$ An important cause of poor CRT response is a suboptimal placed LV lead. ${ }^{5}$ A suboptimal placed LV lead may hamper successful resynchronization because the distally wedged pacing electrodes may be close to an infarcted region or remote from the electromechanical hot spot. ${ }^{6}$ To reach this hot spot, quadripolar LV leads may be of beneficial use. ${ }^{7}$ Because the tip of a quadripolar lead is often wedged in a tributary of the coronary sinus, its electrodes will span a range from apical to basal regions of the LV wall. ${ }^{8}$ Despite several studies on quadripolar leads, ${ }^{9,10}$ the exact benefit of the additional pacing sites on LV function remains relatively unknown. ${ }^{8}$ Most studies only compared the benefit of the proximal electrodes to the distal electrode. 9,10 These studies were small, used noninvasive techniques to measure acute hemodynamic response with low signal-to-noise ratios, or a fixed atrioventricular (AV) delay. ${ }^{8}$ Moreover, noninvasive methods to select the optimal electrode of a quadripolar LV lead are lacking. Potential optimization methods are parameters of electric delay derived from the ECG or intracardiac electrogram. The QLV interval is one of these electric delays, defined by the delay between Q on the surface ECG and local LV depolarization on the intracardiac electrogram at a given LV pacing site (Figure 1). ${ }^{11}$ The QLV may be normalized using the intrinsic QRS duration (QLV/QRSd). ${ }^{12}$ A few studies reported that an apical or anterior LV lead position may be suboptimal for CRT response, whereas electrodes placed basal or midventricular in a lateral position yield more favorable response. ${ }^{13,14}$ However, these studies compared bipolar LV leads in different patients, without taking interpatient variability in consideration.

The hypothesis of this study is that biventricular pacing at a site with the largest QLV/QRSd ratio provides the largest acute hemodynamic response. Therefore, the aim of the study was to associate the acute hemodynamic response of each electrode of the quadripolar LV lead, measured by invasive pressure-volume loops (PV loops), with electric and anatomic parameters. 


\section{MATERIALS AND METHODS}

\section{Patient Cohort}

The observational OPTICARE-QLV study (Optimization of Cardiac Resynchronizaton Therapy With a Quadripolar Left Ventricular Lead) was performed between 2014 and 2017 in 3 university medical centers (University Medical Center Utrecht, Utrecht; VU University Medical Center, Amsterdam; and Maastricht University Medical Center, Maastricht; all in the Netherlands). A total of 51 consecutive patients planned for CRT implantation were included, with moderate-tosevere heart failure (ie, New York Heart Association class II or III), LV ejection fraction $\leq 35 \%$, optimal pharmacological therapy, sinus rhythm, and a left bundle branch block (LBBB) according to Strauss criteria. ${ }^{15}$ Exclusion criteria were severe aortic valve stenosis, mechanical aortic valve replacement, and the presence of LV thrombus. All subjects gave written informed consent. The study was performed according to the Declaration of Helsinki and in agreement with the local medical ethics committees. Because the data of this study is also used for future publications, the data, analytic methods, and study materials will not be made available to other researchers for purposes of reproducing the results or replicating the procedure.

\section{CRT Implantation}

All patients underwent electrocardiographic and echocardiographic examination and cardiac magnetic resonance imaging before device implantation. Cardiac magnetic resonance (or echocardiography)-derived LV volumes were used to calibrate the conductance catheter-derived baseline volumes. CRT implantation was performed under local anesthesia. Right ventricular (RV) and right atrial (RA) leads were placed transvenously at conventional positions. The quadripolar LV lead (Quartet 1458Q; St. Jude Medical, Saint Paul, MN) was placed in one of the coronary veins overlying the LV free wall. A site in the lateral, anterolateral, or posterolateral position was preferred. After electrophysiological measurements, the 3 leads were connected to a St. Jude Medical CRT device.

\section{Electrophysiological Measurements}

Electrophysiological measurements were performed using an on-site dedicated electrophysiological system. Electrophysiological system settings of the 3 participating centers were matched to study protocols. The electrophysiological system was used to record simultaneous registrations of the 12-lead surface ECG and the 3 implanted leads. Delays of specific pacing modalities were recorded, and delays between pacing artefacts and local depolarization at the leads were measured. For each electrode (ie, D1, M2, M3, and P4), QLV was defined as the intrinsic conduction time from first $Q$ on the surface ECG to local LV depolarization at the electrode of the quadripolar LV lead (QLV; Figure 1). The ratio between QLV and the intrinsic QRS duration was also calculated for each electrode (QLV/QRSd). We used QLV/QRSd to uniform results on conduction delay between patients. Next, RA pacing-to-RV sensing interval was measured and used to calculate the patient-specific AV delays. The delay between RV pacing-to-LV sensing interval
(RVp-LVs) was measured as a parameter of paced interventricular conduction delay.

\section{Hemodynamic Measurements}

Directly after device implantation, a dedicated PV-loop conductance catheter (CD Leycom; Zoetermeer, The Netherlands) was inserted via the femoral artery and placed in the LV cavity. PV loops were recorded for biventricular pacing with each individual electrode of the quadripolar lead, in-between baseline recordings during intrinsic conduction. The LV electrode was used as a cathode with the RV coil as anode, resulting in 4 different pacing vectors. Only configurations without phrenic nerve stimulation close to the myocardial pacing threshold were used. For each electrode, $4 \mathrm{AV}$ delays were determined to approximate 20\%, 40\%, $60 \%$, and $80 \%$ of the patient's intrinsic AV conduction time (RA pacing-to-RV sensing interval). The interventricular delay was programed to $40 \mathrm{~ms}$ LV first because LV pacing $40 \mathrm{~ms}$ before RV pacing is favorable in $80 \%$ of patients with CRT. ${ }^{16}$ The order in which the electrodes were tested was varied between patients. To keep heart rate constant, PV loops were recorded during atrial pacing, with a frequency of 5 to 10 beats per minute above intrinsic rhythm. Recordings lasted 60 beats per pacing configuration, after excluding all inappropriate beats (ie, extra systoles with 1 preceding and 2 subsequent beats). PV loops during intrinsic conduction (ie, RA pacing) were recorded for 30 beats at the same heart rate. The area of the PV loop was used to calculate stroke work (SW). To account for baseline drift, ${ }^{17}$ the effect of biventricular pacing was quantified as change in SW, calculated as a percentage change ( $\Delta \% \mathrm{SW})$ compared with the mean of the 2 adjoining baseline measurements. For each electrode, a parabolic curve was fitted to change in $\Delta \%$ SW obtained from the $4 \mathrm{AV}$ delays (Figure 1). The highest value of each parabolic curve was noted as the optimal change in $\Delta \% \mathrm{SW}$ and corresponding AV delay for the specific electrode.

\section{Lead Position}

After lead placement, fluoroscopy images were made in the left anterior oblique $40^{\circ}$ and in the right anterior oblique $30^{\circ}$ view to determine the specific position of each quadripolar LV lead electrode in the longitudinal direction (Figure 2). On the right anterior oblique $30^{\circ}$ view, the distance between base of the LV and each electrode was divided by the distance between base and apex, to obtain the right anterior oblique ratio (Figure 2). The right anterior oblique ratio was divided into 3 even groups, resulting in basal, mid, and apical positioned electrodes. For the left anterior oblique $40^{\circ}$ view, the ventricle was divided into 5 equally sized regions overlying the LV free wall in the circumferential direction (ie, anterior, anterolateral, lateral, posterolateral, and posterior). ${ }^{7}$

\section{Statistical Analysis}

Statistical analysis was performed using SPSS statistics, version 23 (IBM, Armonk, NY). Data are presented as mean \pm SD or median and interquartile range, based on normality of data. Of certain parameters, the variation between electrodes was calculated for each individual 


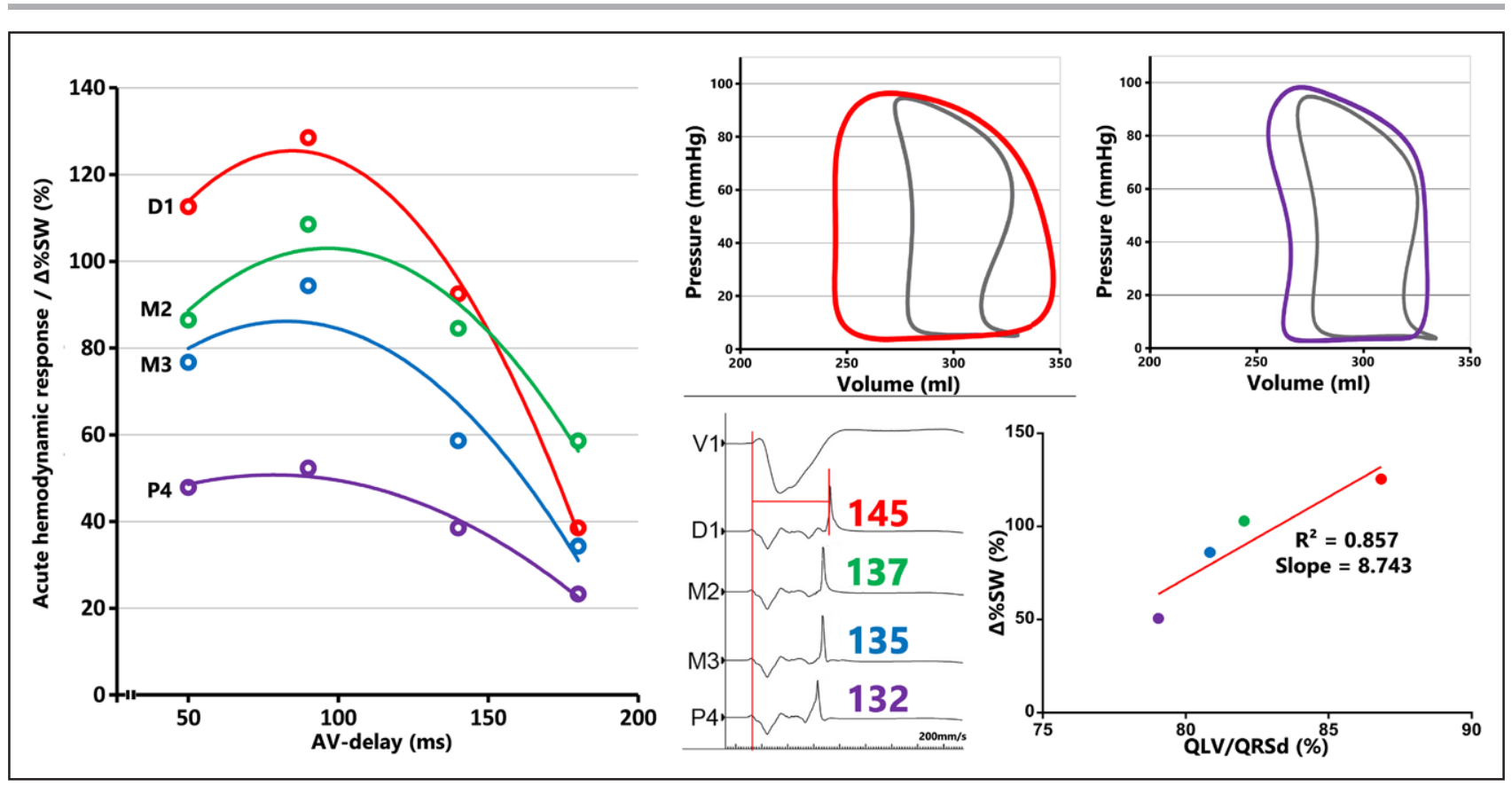

Figure 1. Method to determine the optimal pacing site of CRT with a quadripolar left ventricular (LV) lead.

The acute hemodynamic response is determined by calculating the increase in stroke work $(\Delta \%$ SW) of pressure-volume (PV) loops of 4 atrioventricular (AV) delays and 4 electrodes compared with loops during right atrial pacing with intrinsic conduction (grey PV loops). PV loops of D1 (red) and M2 (green) are displayed in the (upper right) corner. For each tested $\mathrm{AV}$ delay and electrode, $\triangle \% \mathrm{SW}$ is plotted in the (left). Delays are determined between Q on the surface ECG (V1) and local LV depolarization at the electrodes of the quadripolar lead (QLV; middle lower). The QLV/QRSd ratio is plotted against $\Delta \% \mathrm{SW}$ of each electrode at the optimal AV delay, and a trend line is fitted (lower right). Electrode colors: D1, red; M2, green; M3, blue; P4, purple.

patient by subtracting the lowest value from the highest value. The average variation and SD of the entire cohort were calculated with these values. To account for repeated measurements, differences in observed parameters between electrodes were compared in generalized estimated equation (GEE), with pairwise comparison. GEEs were also used to assess the value of expected predictors (ie, electrode position in longitudinal and circumferential direction, RVp-LVs, QLV, and QLV/QRSd ratio) of change in $\triangle \% \mathrm{SW}$ on a group level. All parameters were tested separately, whereas both parameters on anatomic position were combined, after which each parameter with $P<0.10$ was incorporated in a combined model. In case of significance of QLV and QLV/QRSd, a single parameter was chosen based on the highest $\beta$ coefficient and $P$ value. The relation between hemodynamic response $(\Delta \% \mathrm{SW})$ and QLV/QRSd of all 4 electrodes was calculated for each patient. A line was fitted to the 4 data points, of which the coefficient of determination and slope were noted (Figure 1). Patients were divided in 2 groups based on the slope: patients with a positive slope and a negative slope. The average slope of all patients reflects the relation between QLV/QRSd and change in $\triangle \% \mathrm{SW}$. The 2 groups were compared on baseline parameters using an independent $t$ test or Mann-Whitney $U$ test. A $\chi^{2}$ test was used for categorical variables. A $P$ value $<0.05$ was considered significant for the GEE. Because of the large number of comparisons, a $P$ value $<0.01$ was considered significant for all remaining tests.

\section{RESULTS}

Fifty-one patients were included prospectively in the study, of which 3 were excluded from the analysis because of unreliable baseline PV loops (Table 1). Twentysix patients were included in the University Medical Center Utrecht, 16 in the VU University Medical Center, and 6 in het Maastricht University Medical Center. Unacceptably high pacing thresholds precluded using electrode M2 in 3 patients and electrode P4 in 3 other patients. Values in the remaining 48 patients and 186 electrodes were as follows: QLV, 140.2 \pm 19.7 ms; QLV/QRSd, 79.9 $\pm 9.2 \%$; and RVp-LVs, $146.4 \pm 23.0$ ms (Table 1). In the longitudinal direction, distal electrodes (ie, D1 and M2) were more often positioned apical, whereas the position of proximal electrodes (ie, M3 and P4) was more often basal (Table 2). In the left anterior oblique view, there were no significant differences in positioning of the electrodes. Overall, most electrodes were positioned in a lateral segment $(n=108 ; 58 \%)$. There was no apparent resemblance between the bull's-eye of QLV/QRSd and acute hemodynamic response (Figure 3). Large differences in QLV/QRSd were primarily seen in the anterolateral positioned electrodes, with higher values in the basal segment compared with the apical segment. $\triangle \%$ SW showed lower values in posterolateral and posterior positioned electrodes, whereas $\Delta \% \mathrm{dP}_{\mathrm{dt}}$ max was 


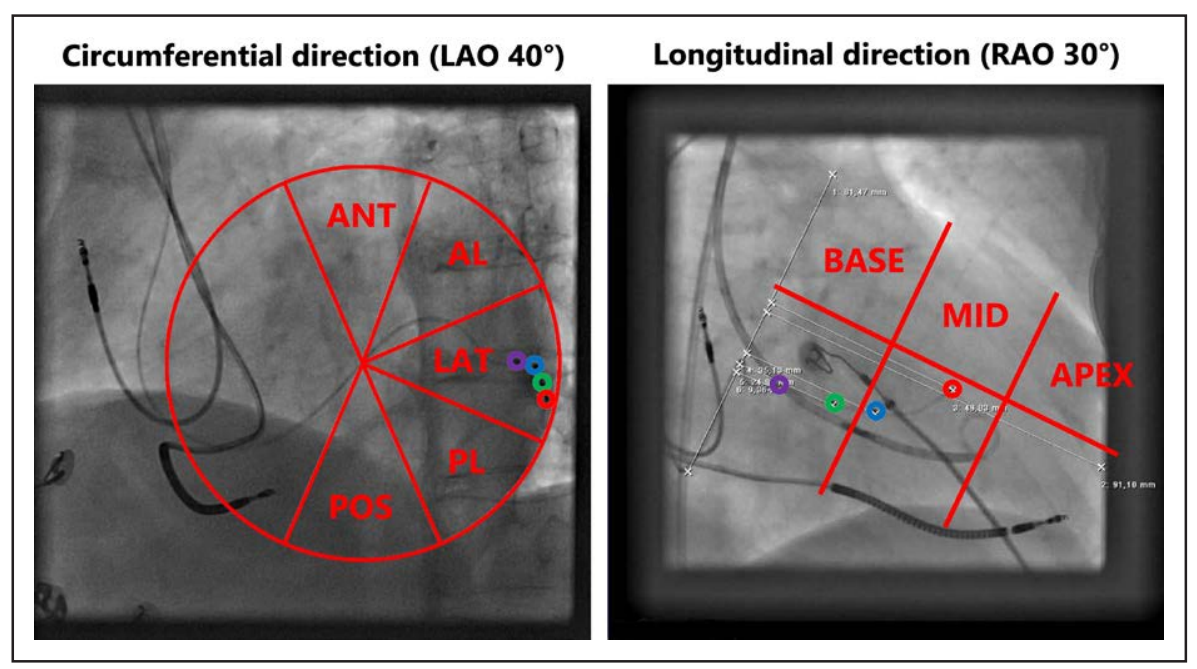

Figure 2. Anatomic position of the quadripolar left ventricular (LV) lead electrodes.

The quadripolar LV lead and electrode position are determined using fluoroscopy in 2 views. In the circumferential direction, the left anterior oblique (LAO) $40^{\circ}$ view was used to divide the LV in an anterior (ANT), anterolateral (AL), lateral (LAT), posterolateral (PL), and posterior segment (POS). In the longitudinal direction, the LV is divided into 3 evenly spaced segments based on the right anterior oblique (RAO) $30^{\circ}$ view: base, mid, and apex. The most distal electrode (D1) is red; the first mid electrode (M2), green; the second mid electrode (M3), blue; and the proximal electrode (P4), purple.

the lowest in the posterior positioned electrodes. On average, QLV/QRSd of the distal electrode (D1) was significantly lower compared with the other 3 electrodes, although the variation between the electrodes was only $8.8 \pm 4.7 \%$ (Table 2 ). RVp-LVs delay showed larger and significant differences between all electrodes (RVp-LVs variation, $27.8 \pm 13.2 \mathrm{~ms}$ ), with the lowest values for the distal electrode, increasing toward the proximal electrode. The pacing threshold of electrode P4 was often higher, whereas phrenic nerve stimulation occurred less using this electrode. Despite these differences in electric properties of the electrodes, no electrode consistently provided the largest increase in $\Delta \%$ SW (D1 in 17 [35\%], M2 in 10 [21\%], M3 in 6 [13\%], and P4 in 15 [31\%] patients). The mean acute hemodynamic response of biventricular pacing was $68.9 \pm 59.3$ for $\Delta \%$ SW and $13.3 \pm 9.5$ for $\Delta \% \mathrm{dP}^{\mathrm{d}} \mathrm{dt}_{\max }$. The variation in $\Delta \% \mathrm{SW}$ had a large distribution between patients (Figure 4), mean variation $\Delta \% \mathrm{SW}$ between the electrodes of a quadripolar lead was $38.8 \pm 36.4 \%$, whereas $\Delta \% \mathrm{dP}^{\mathrm{d}} \mathrm{dt}_{\max }$ had a variation of $4.9 \pm 2.9 \%$ (Figure I in the Data Supplement).

\section{Results at Group Level}

Biventricular pacing with the electrode of maximal QLV or QLV/QRSd tended to result toward a smaller increase of $\Delta \% \mathrm{SW}$ compared with selecting the electrode with the highest achievable $\Delta \% \mathrm{SW} \quad(67.8 \pm 51.2$ versus $88.7 \pm 63.8 \% \mathrm{SW} ; P=0.05)$. The difference between biventricular pacing with the electrode with the highest RVpLVs was significant compared with the highest achievable $\Delta \%$ SW $(67.8 \pm 51.2$ versus $88.7 \pm 63.8 \%$ SW; $P<0.001)$. A significant association between \%SW and QLV/QRSd was observed at group level (Table 3). This analysis showed that with each percentage increase in QLV/QRSd, $\Delta \% S W$ increased with $0.9 \%$ in a single-variable model and $0.8 \%$ in a combined model. A combined GEE model of anatomic position also showed a significant association between electrode position in the circumferential direction and $\Delta \% \mathrm{SW}$ change. Electrodes in the anterolateral or lateral position were associated with $\approx 10 \%$ higher $\Delta \% \mathrm{SW}$ values compared with posterior and posterolateral positioned electrodes ( $P<0.05$ for both comparisons). There was no association between change in $\Delta \% \mathrm{SW}$ and electrode position in a longitudinal direction or RVp-LVs. A combined GEE model of QLV/QRSd and electrode position in the circumferential direction showed a significant association of QLV/QRSd with change in $\Delta \% \mathrm{SW}$ but no significant association of the electrode position.

\section{Results for the Individual Patient}

Despite the significant relation between QLV/QRSd and $\Delta \% S W$ at the group level described above, there was considerable heterogeneity in this relation in individual patients. The association between $\Delta \% \mathrm{SW}$ and QLV/QRSd had a direct relation (ie, positive slope) for 24 patients but an inverse relation (ie, negative slope) for the remaining 24 patients (Figure 5). The $R^{2}$ tended to be higher in patients with a direct relation (0.570 \pm 0.319$)$, whereas it was lower for the patients with an inverse relation $(0.377 \pm 0.320 ; P=0.05)$. These poorer correlations in case of an inverse relation may be explained by the smaller variation in $\Delta \% \mathrm{SW}$ in the patients with inverse versus those with a direct relation ( $26.8 \pm 20.0$ versus $50.8 \pm 44.7 \Delta \% S W ; P=0.02$; Fig- 
Table 1. Baseline Characteristics

\begin{tabular}{|c|c|c|c|c|}
\hline Parameters & $\begin{array}{l}\text { Total Cohort } \\
(\mathrm{N}=48)\end{array}$ & $\begin{array}{l}\text { Direct Relation } \\
\text { QLV/QRSd-\%SW } \\
(n=24)\end{array}$ & $\begin{array}{l}\text { Inverse Relation } \\
\text { QLV/QRSd-\%SW } \\
\quad(n=24)\end{array}$ & $P$ Value \\
\hline Age, y & $65.9 \pm 9.5$ & $66.2 \pm 10.2$ & $65.7 \pm 8.8$ & 0.845 \\
\hline Sex, n; men (\%) & $31(65 \%)$ & $17(71 \%)$ & $14(58 \%)$ & 0.547 \\
\hline Type of cardiomyopathy, n; ICM (\%) & $13(27 \%)$ & $7(29 \%)$ & $10(42 \%)$ & 0.547 \\
\hline NYHA class II, n (\%) & $33(69 \%)$ & $16(67 \%)$ & $17(71 \%)$ & 1.000 \\
\hline NYHA class III, n (\%) & $15(31 \%)$ & $8(33 \%)$ & $7(29 \%)$ & \\
\hline PR duration, ms & $182.8 \pm 31.3$ & $186.6 \pm 33.7$ & $179 \pm 28.8$ & 0.403 \\
\hline QRS duration, ms & $175.6 \pm 13.6$ & $174.2 \pm 12.6$ & $176.9 \pm 14.6$ & 0.504 \\
\hline Mean QLV, ms & $140.2 \pm 19.7$ & $134.2 \pm 21.8$ & $146.3 \pm 15.5$ & 0.032 \\
\hline Mean QLV/QRSd, \% & $79.9 \pm 9.2$ & $77.1 \pm 11.5$ & $82.7 \pm 4.9$ & 0.034 \\
\hline QLV/QRSd variation, \% & $8.8 \pm 4.7$ & $8.0 \pm 3.8$ & $9.6 \pm 5.5$ & 0.227 \\
\hline Mean RVp-LVs, ms & $146.4 \pm 23.0$ & $145.2 \pm 28.2$ & $147.6 \pm 17.2$ & 0.726 \\
\hline LV EDV, mL & $210.8 \pm 66.0$ & $233.6 \pm 69.9$ & $188.1 \pm 54.1$ & 0.015 \\
\hline LV ESV, mL & $154.3 \pm 61.4$ & $174.9 \pm 66.6$ & $133.7 \pm 48.9$ & 0.018 \\
\hline LV EF, \% & $28.5 \pm 8.4$ & $26.3 \pm 6.7$ & $30.4 \pm 8.8$ & 0.067 \\
\hline LV EDD, mm & $61.6 \pm 7.5$ & $63.0 \pm 8.7$ & $60.2 \pm 6.1$ & 0.206 \\
\hline Creatinine & $90.1 \pm 22.7$ & $92.8 \pm 24.1$ & $86.3 \pm 21.6$ & 0.336 \\
\hline Log BNP & $1.89 \pm 0.54$ & $2.03 \pm 0.59$ & $1.76 \pm 0.48$ & 0.125 \\
\hline \multicolumn{5}{|l|}{ Medication, n (\%) } \\
\hline ACE inhibitor or ATIl antagonist & $47(98 \%)$ & $24(100 \%)$ & $23(96 \%)$ & 1.000 \\
\hline$\beta$-Blocker & $42(88 \%)$ & $22(92 \%)$ & $20(83 \%)$ & 0.724 \\
\hline Diuretic & $32(67 \%)$ & $16(67 \%)$ & $16(67 \%)$ & 1.000 \\
\hline Aldosterone antagonist & $29(60 \%)$ & $11(46 \%)$ & $18(75 \%)$ & 0.075 \\
\hline Anticoagulant & $30(63 \%)$ & $12(50 \%)$ & $18(75 \%)$ & 0.135 \\
\hline \multicolumn{5}{|l|}{ Comorbidities, n (\%) } \\
\hline Hypertension & $17(71 \%)$ & $5(21 \%)$ & $12(50 \%)$ & 0.069 \\
\hline Renal failure & $4(17 \%)$ & $1(4 \%)$ & $3(13 \%)$ & 0.609 \\
\hline \multicolumn{5}{|l|}{ Circumferential electrode position, n (\%) } \\
\hline Anterior & 0 & 0 & 0 & 0.021 \\
\hline Anterolateral & $31(17 \%)$ & $18(20 \%)$ & $13(14 \%)$ & \\
\hline Lateral & $108(58 \%)$ & $44(45 \%)$ & $64(68 \%)$ & \\
\hline Posterolateral & $44(24 \%)$ & $27(29 \%)$ & $17(18 \%)$ & \\
\hline Posterior & $3(2 \%)$ & $3(3 \%)$ & 0 & \\
\hline \multicolumn{5}{|l|}{ Longitudinal electrode position, n (\%) } \\
\hline Basal & $60(32 \%)$ & $28(30 \%)$ & $32(34 \%)$ & 0.053 \\
\hline Mid & $101(54 \%)$ & $46(50 \%)$ & $55(59 \%)$ & \\
\hline Apical & $25(13 \%)$ & $18(20 \%)$ & $7(7 \%)$ & \\
\hline
\end{tabular}

Direct relation: patients with a direct relation between QLV/QRSd and change in stroke work ( $\triangle \% S W$ ). Inverted relation: patients with an inverse relation between QLV/QRSd and $\Delta \% S W$. ACE indicates angiotensin-converting enzyme; ATII, angiotensin receptor II; BNP, brain natriuretic peptide; EDD, end-diastolic diameter; EDV, end-diastolic volume; EF, ejection fraction; ESV, end-systolic volume; ICM, ischemic cardiomyopathy; LV, left ventricular; LVs, left ventricular sensing; NYHA, New York Heart Association; QLV, Q to LV sensing delay; QLV/QRSd, ratio of QLV and QRS duration; RVp, right ventricular pacing; and SW, stroke work.

ure 4). However, mean $\Delta \% \mathrm{SW}$ did not differ between patients with a direct $(67.8 \Delta \% \mathrm{SW})$ or inverse relation (70.6 $\Delta \% S W ; P=0.87$ ). Comparing baseline characteristics of patients with a direct and inverse QLV/QRSd$\triangle \%$ SW relation revealed no significant differences
(Table 1). However, QLV and QLV/QRSd values tended to be lower, whereas LV end-diastolic and end-systolic volumes tended to be larger for patients with a direct relation. Accordingly, LV ejection fraction tended to be lower in patients with a direct QLV/QRSd-\%SW relation. 
van Everdingen et al; QLV to Optimize CRT With a Quadripolar LV Lead

Table 2. Electrode Characteristics

\begin{tabular}{|c|c|c|c|c|c|}
\hline Parameters $(n=48)$ & D1 $(n=48)$ & $M 2(n=45)$ & M3 $(n=48)$ & P4 $(n=45)$ & $P$ Value \\
\hline Pacing threshold, V; median (IQR) & $0.7(0.3-1.8)$ & $0.7(0.4-2.2)$ & $0.6(0.4-1.8)$ & $1.8(0.5-5.2)^{*}$ & $<0.001 \dagger$ \\
\hline PNS threshold, V; median (IQR) & $10.0(2.0-10.0) \ddagger$ & $10.0(1.5-10.0)$ & $10.0(2.9-10)$ & $10.0(7.0-10.0) \ddagger$ & $0.002 \dagger$ \\
\hline $\mathrm{QLV}, \mathrm{ms} ;$ mean $\pm \mathrm{SD}$ & $135.5 \pm 19.2^{*}$ & $142.1 \pm 20.2$ & $141.9 \pm 21.1$ & $144.3 \pm 20.0$ & $<0.001 \dagger$ \\
\hline QLV/QRSd, \%; mean $\pm S D$ & $77.1 \pm 8.7^{*}$ & $80.6 \pm 9.7$ & $80.8 \pm 10.0$ & $82.1 \pm 9.8$ & $<0.001 \dagger$ \\
\hline $\mathrm{RVp}-\mathrm{LV}$ s, ms; mean $\pm \mathrm{SD}$ & $131.8 \pm 23.7 *$ & $144.9 \pm 23.9 *$ & $151.3 \pm 23.8^{*}$ & $158.1 \pm 24.5^{*}$ & $<0.001 \dagger$ \\
\hline$\Delta \% \mathrm{SW}, \% ;$ mean $\pm \mathrm{SD}$ & $67.4 \pm 55.0$ & $74.4 \pm 55.4$ & $70.9 \pm 64.4$ & $63.1 \pm 63.2$ & 0.011 \\
\hline$\Delta \% \mathrm{dP} / \mathrm{dt}_{\max ^{\prime}} \% ;$ mean $\pm \mathrm{SD}$ & $13.5 \pm 8.8$ & $13.5 \pm 9.5$ & $12.7 \pm 9.3$ & $13.3 \pm 10.6$ & 0.255 \\
\hline \multicolumn{6}{|l|}{ Longitudinal position, n (\%) } \\
\hline Basal & $0(0 \%)$ & $5(10 \%)$ & $22(46 \%)$ & $33(73 \%)$ & $<0.001 \dagger$ \\
\hline Mid & $34(71 \%)$ & $34(71 \%)$ & $34(48 \%)$ & $10(21 \%)$ & \\
\hline Apical & $14(29 \%)$ & $6(13 \%)$ & $3(6 \%)$ & $2(4 \%)$ & \\
\hline \multicolumn{6}{|l|}{ Circumferential position, n (\%) } \\
\hline Anterior & 0 & 0 & 0 & 0 & 0.270 \\
\hline Anterolateral & $4(8 \%)$ & $7(16 \%)$ & $8(17 \%)$ & $12(25 \%)$ & \\
\hline Lateral & $27(56 \%)$ & $30(67 \%)$ & $28(58 \%)$ & $23(51 \%)$ & \\
\hline Posterolateral & $17(35 \%)$ & $7(16 \%)$ & $11(23 \%)$ & $9(20 \%)$ & \\
\hline Posterior & 0 & $1(2 \%)$ & $1(2 \%)$ & $1(2 \%)$ & \\
\hline
\end{tabular}

PNS thresholds were measured to a maximum of $10 \mathrm{~V}$. IQR indicates interquartile range; LVs, left ventricular sensing; PNS, phrenic nerve stimulation; QLV, Q to LV sensing delay; QLV/QRSd, ratio of QLV and QRS duration; RVp, right ventricular pacing; and SW, stroke work.

${ }^{*} P<0.001$ compared with all other electrodes.

$+P<0.05$ between electrodes.

$\ddagger P<0.01$ between indicated electrodes.

There tended to be more electrodes positioned in a posterolateral or posterior position in patients with a direct relation, whereas there was a trend toward more apically positioned electrodes in patients with an inverse QLV/QRSd-\%SW relation.

\section{DISCUSSION}

The present study showed a statistically significant relation between intrinsic ventricular conduction time (QLV/ QRSd) and acute hemodynamic response ( $\Delta \% \mathrm{SW})$ at group level. However, only half of the patients showed a direct relation between QLV/QRSd and $\Delta \%$ SW, whereas the other half had an inverse relation. Therefore, QLV or QLV/QRSd may not predict the electrode of a quadripolar LV lead that provides the largest hemodynamic response at the individual level. There was also no association between the paced interventricular conduction time (RVp-LVs) and $\Delta \% \mathrm{SW}$. Nevertheless, anatomic position did reveal favorable sites for LV pacing, namely in the anterolateral or lateral position. Moreover, optimization of CRT with a quadripolar LV lead is important because there was a large intraindividual variation in the acute hemodynamic response of the 4 electrodes.

\section{Optimal Pacing Site}

Our results indicate a discrepancy between the optimal pacing site for the entire cohort and for the individual patient. Although a longer QLV was significantly associated with a better hemodynamic response at group level, the relation between QLV and response ranged from strongly positive to inverse between individual patients. This discrepancy may be explained by several factors. Most leads were positioned in an area of pronounced delayed activation, with high QLV/QRSd values. Also, the variation in QLV between the 4 electrodes was relatively small. In animal studies, it has been shown that, especially in a model of nonischemic heart failure, there is a large region within the LV wall that, when paced, provides a significant hemodynamic effect. ${ }^{18}$ Therefore, QLV/QRSd seems not predictive for the hemodynamic response within late activated areas, especially because some measurement variability has to be taken into account. In line with this idea is the observation that patients with a direct relation tended to have lower QLV/QRSd values, potentially caused by suboptimally placed LV leads. This may imply that suboptimally placed leads may benefit more from selection of the pacing site with the highest change in $\Delta \% \mathrm{SW}$. The weak but significant association between QLV/QRSd and acute hemodynamic response on group level is of interest. The association indicates that pacing in a region with prolonged QLV/QRSd benefits acute hemodynamic response. However, it does not imply that increase in QLV/QRSd will automatically lead to an increase in SW in each patient. In contrast to our results, Zanon et al ${ }^{19}$ found a strong direct relation between QLV and 
Table 3. Prediction of Change in Percentage Change in Stroke Work

\begin{tabular}{|c|c|c|c|}
\hline & $\beta$-Coefficient & SE $(95 \% \mathrm{Cl})$ & $P$ Value \\
\hline \multicolumn{4}{|c|}{ Single-variable models (GEE)_electric delays } \\
\hline QLV & 0.579 & $0.193(0.202$ to 0.956$)$ & $0.003^{*}$ \\
\hline QLV/QRSd & 0.934 & $0.332(0.283$ to 1.586$)$ & $0.005^{*}$ \\
\hline RVp-LVs & 0.076 & $0.245(-0.404$ to 0.556$)$ & 0.756 \\
\hline \multicolumn{4}{|c|}{ Combined model (GEE)-anatomic position } \\
\hline \multicolumn{4}{|l|}{ Longitudinal position } \\
\hline Basal & -0.226 & $8.755(-17.386$ to 16.935$)$ & 0.979 \\
\hline Mid & 4.157 & $7.109(-9.776$ to 18.090$)$ & 0.559 \\
\hline Apical & $0+$ & $\ldots$ & $\ldots$ \\
\hline \multicolumn{4}{|l|}{ Circumferential position } \\
\hline Anterolateral & 11.619 & $5.682(0.483$ to 22.755$)$ & $0.041 *$ \\
\hline Lateral & 9.068 & $4.543(0.226$ to 17.909$)$ & $0.044^{*}$ \\
\hline Posterolateral or posterior & $0 \dagger$ & $\cdots$ & $\ldots$ \\
\hline \multicolumn{4}{|c|}{ Combined model (GEE)—significant predictors } \\
\hline QLV/QRSd & 0.809 & $0.351(0.121$ to 1.497$)$ & $0.021 *$ \\
\hline \multicolumn{4}{|l|}{ Circumferential position } \\
\hline Anterolateral & 4.527 & $5.704(-6.651$ to 15.706$)$ & 0.427 \\
\hline Lateral & 4.916 & $4.520(-3.944$ to 13.776$)$ & 0.227 \\
\hline Posterolateral or posterior & $0+$ & $\ldots$ & $\ldots$ \\
\hline
\end{tabular}

Single-variable models show the results of the GEE of each parameter. The parameters with $P$ values $<0.10$ were combined in a final model (ie, GEE). The categories posterolateral and posterior were combined because there were only 3 electrodes positioned posterior. CI indicates confidence interval; GEE, generalized estimated equation; LVs, left ventricular sensing; QLV, Q to LV sensing delay; QLV/QRSd, ratio of QLV and QRS duration; and RVp, right ventricular pacing.

* Statistically significant.

†Set to zero because the parameter is redundant.

hemodynamic response, which was apparent in each patient. However, there are 4 main differences between their study and ours. First, we used SW instead of dP/ $\mathrm{dt}_{\text {max }}$. Although $\mathrm{dP} / \mathrm{dt}_{\max }$ is limited to pressure changes in the isovolumetric contraction phase, SW incorporates pressure and volume changes of the entire cardiac cycle. ${ }^{20}$ Second, we only included patients with LBBB, as opposed to including also patients with intraventricular conduction delay and right bundle branch block. ${ }^{19}$ The latter had lower QLV values and a less favorable substrate for CRT response. Third, we optimized the AV delay at each pacing configuration and programmed the interventricular pacing delay to $40 \mathrm{~ms}$ LV first. A study of our own group showed that pacing the LV 40 ms before the RV improved CRT response in $80 \%$ of all patients. ${ }^{16}$ Fourth and perhaps most important, although we only tested the 4 electrodes of a single quadripolar lead at a single target vein, Zanon et al tested $\leq 11$ pacing sites per patient in multiple cardiac veins, thereby including suboptimal sites with a short QLV. Thereby a large range of QLV values was obtained, larger than what is present in a single vein. The correlation between QLV and acute hemodynamic response seems driven by the shorter QLV values ( $<95 \mathrm{~ms}$ ), which are below the cutoff value for CRT response defined by Gold et al. ${ }^{11}$ The lack of correlation between QLV/
QRSd and hemodynamic response in a single vein is in line with results from the iSPOT study (Left Ventricular Multispot Pacing for CRT). ${ }^{21}$ QLV and QLV/QRSd may, therefore, be suitable parameters for lead placement in general, indicating the overall expected benefit, as it is a predictor for acute hemodynamic and long-term CRT response. ${ }^{11,19}$ However, the QLV or QLV/QRSd cannot be used for selection of the optimal electrode of a quadripolar LV lead after lead placement in an already optimal area (ie, anterolateral or lateral).

It could be argued that the lack of a clear QLV- $\Delta \%$ SW relation is because of the fact that not the delay during intrinsic activation but that during RV pacing (a component of biventricular pacing) matters. Because the location of the latest activated region often differs between RV pacing and LBBB activation, 22 we also investigated the relation $\mathrm{RVp}-\mathrm{LV}$ s delay with $\Delta \% \mathrm{SW}$. Because the highest RVp-LVs value was frequently seen at the proximal electrodes, whereas the electrode with the highest change in acute hemodynamic response was heterogeneously distributed between patients, RVp-LVs is also not suitable for optimization. Therefore, optimization of the pacing location within a quadripolar lead seems more complicated than merely selecting the latest activated site during LBBB or RV pacing. A rather good effect is already achieved when pacing at a relatively 


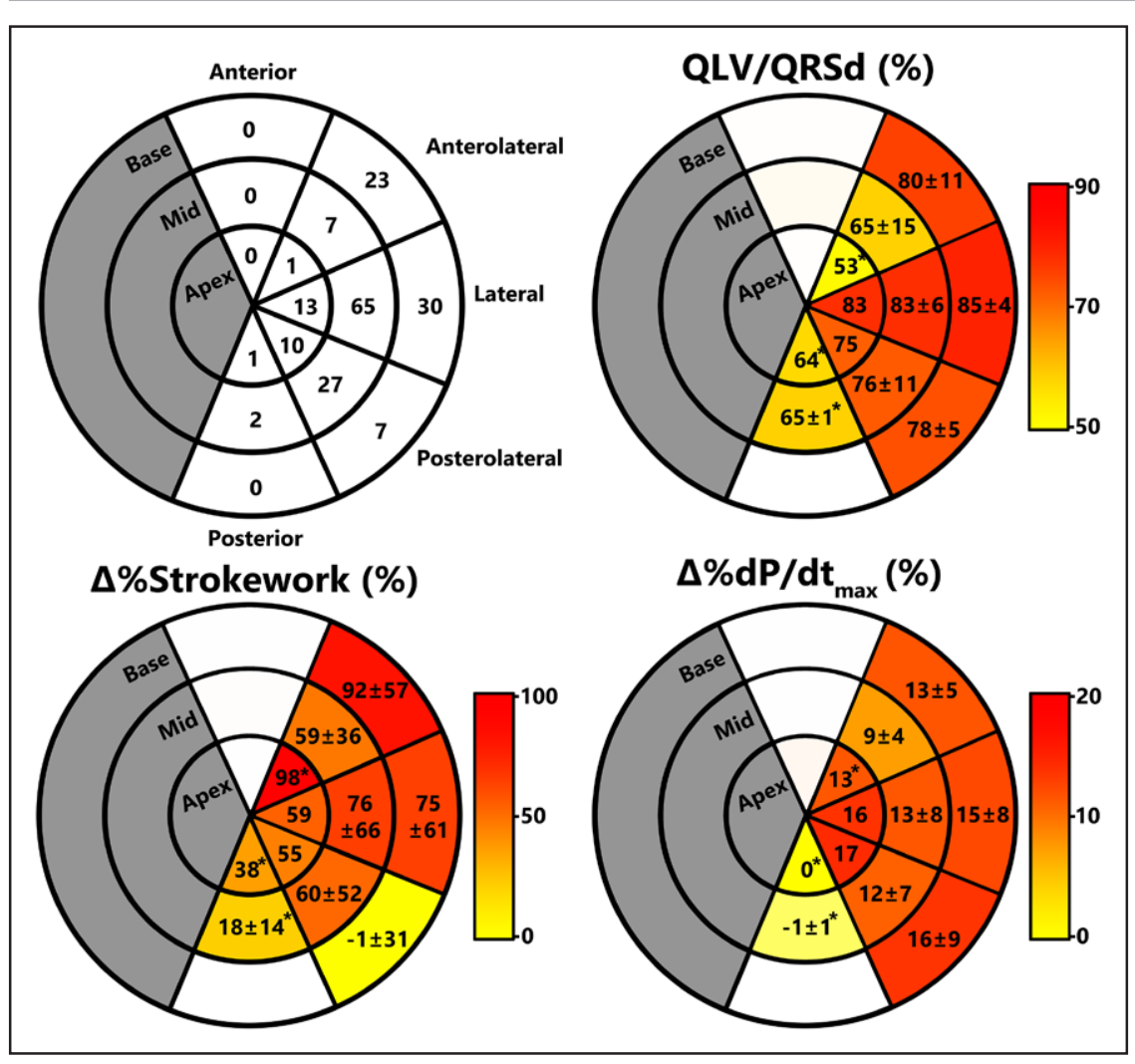

Figure 3. Anatomic representation of electrode position, electric delay, and hemodynamic response. The bull's-eye in the (upper left) corner displays the anatomic position of the 192 electrodes divided into 15 segments. The average and SD of the QLV/QRSd of each segment are displayed in the (upper right) corner. Average acute hemodynamic response in percentage increase in stroke work and $\mathrm{dP} / \mathrm{dt}_{\max }$ of each segment are displayed in the lower 2 bull's-eyes. The 1 basal anterior electrode had no capture and, therefore, no hemodynamic value. *Values represent only 1 or 2 electrodes.

late activated region. An alternative hypothesis would be that the optimal LV pacing site is located at a region with fast LV free wall depolarization. ${ }^{23}$ Such regions proved to be especially located at anterolateral or lateral sites, as has been shown previously. ${ }^{24,25}$ These regions may overlap with areas that are late activated during intrinsic conduction, with prolonged QLV or QLV/QRSd. However, the actual hot spot may differ because the sites with the largest QLV/QRSd values did not always produce the highest increase in $\triangle \% \mathrm{SW}$.

\section{Acute Hemodynamic Effect}

The effect of CRT on increase in SW was relatively large; however, the findings are in line with results from earlier studies. ${ }^{9,26}$ The relatively high $\triangle \% \mathrm{SW}$ may be ascribed to patient selection (ie, strict LBBB and relative low percentage of patients with ischemic cardiomyopathy) and optimization of the pacing configuration and AV delay, recruiting more of the potential substrate. The interindividual difference in the benefit of CRT was large in our study population, which is in line with recent findings. ${ }^{21}$ Previous studies found more variation in $\mathrm{dP} / \mathrm{dt}_{\max }$ between patients or between different veins than pacing sites of a multipolar lead within a single vein. 21,27 However, our study showed a large intraindividual variation in $\Delta \% \mathrm{SW}$ change of the 4 electrodes. Selecting the pacing site of a quadripolar lead is, therefore, important for acute hemodynamic response in a subset of patients.
Optimization of CRT with a quadripolar LV lead using SW from PV loops would result in a favorable longterm response in most patients. ${ }^{20}$ The $20 \%$ increase in $\Delta \% \mathrm{SW}$ cutoff value for response, defined by $\mathrm{De}$ Roest et al, ${ }^{20}$ may result in $9(18 \%)$ nonresponders for biventricular pacing with the distal electrode (ie, conventional (RT) compared with only 4 patients (8\%) for biventricular pacing with the optimal pacing configuration. Multipoint pacing may result in

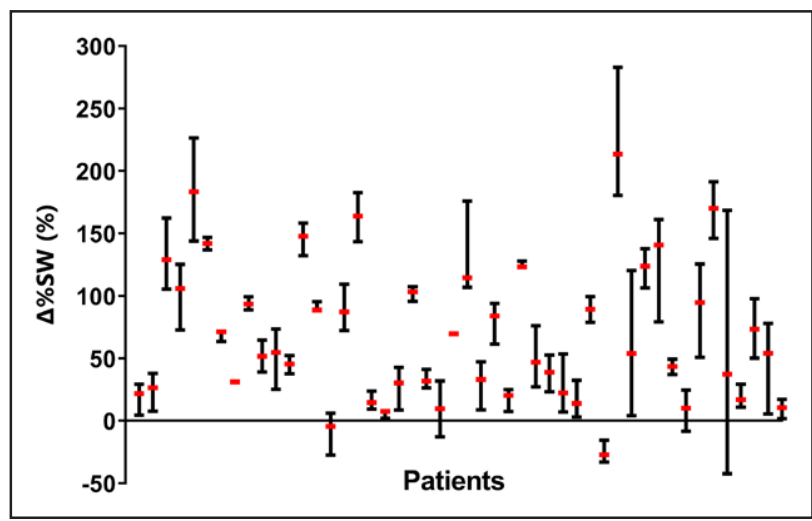

Figure 4. Change in stroke work (SW) per patient. The smallest, largest, and median percentage changes in SW $(\Delta \%$ SW) per patient. The red dashes depict the median; upper and lower bars, the smallest and the largest value obtained with 1 of the 4 electrodes of the quadripolar left ventricular lead. Patients are ranked in the same order as Figure 5; on the slope and direction of the $R^{2}$. 


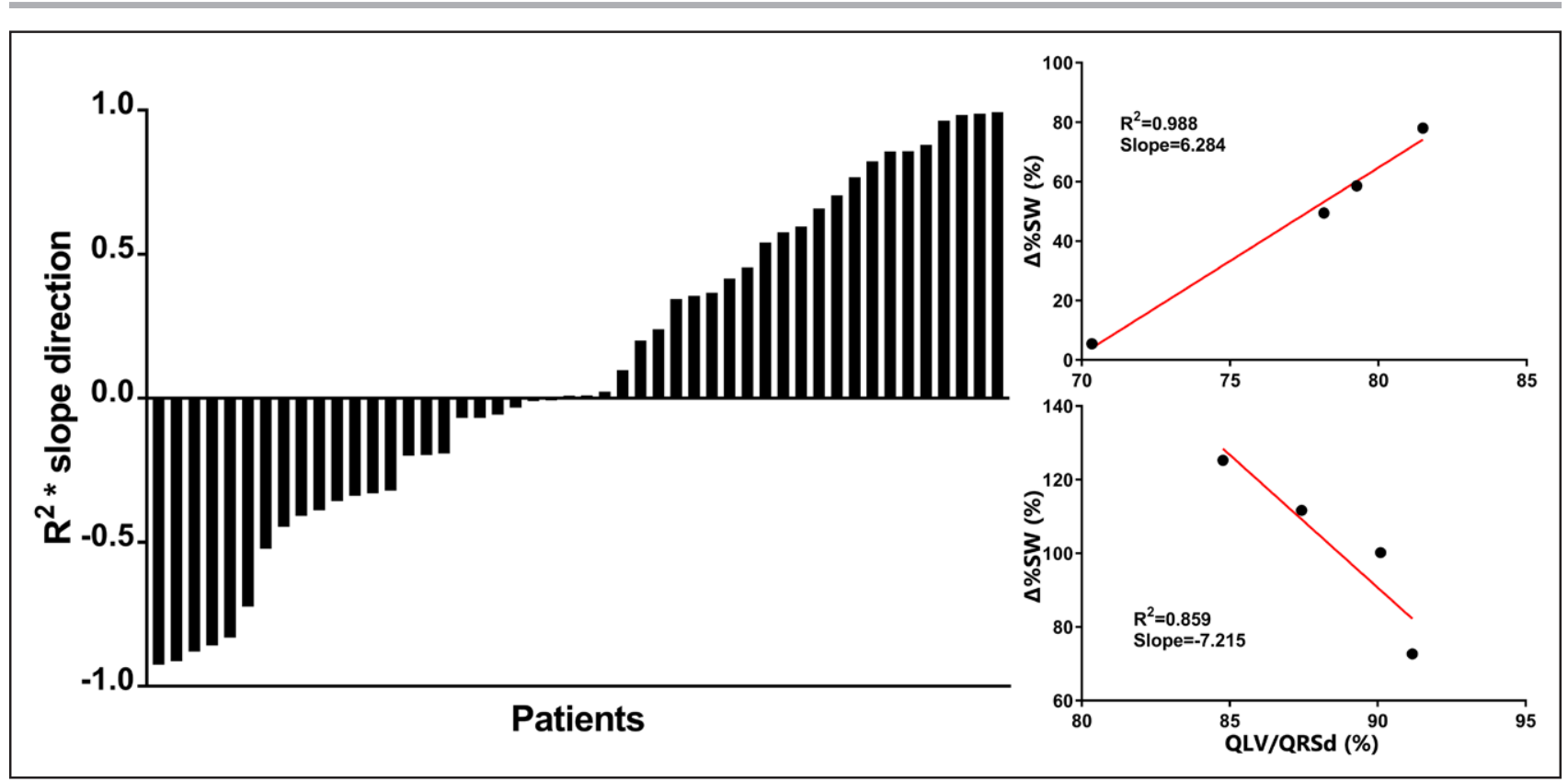

Figure 5. Distribution of the slope and coefficient of determination for percentage changes in SW ( $\Delta \% \mathrm{SW}$ ) and QLV/QRSd.

The slope direction multiplied by the coefficient of determination $\left(R^{2}\right)$ of the trend line fitted to QLV/QRSd and $\Delta \%$ SW for each patient. Values are arranged from the lowest to the highest value. There are 24 patients with a direct relation (positive slope) and 24 with an invert relation (negative slope). Examples of a direct relation (upper right) and an inverse relation (lower right) are shown.

an even greater benefit, ${ }^{28,29}$ which will be addressed in future work. QLV has also been associated with reverse remodeling and volumetric response to CRT. ${ }^{11}$ The association of QLV/QRSd, SW, and $\mathrm{dP} / \mathrm{dt}_{\max }$ with volumetric response in this patient cohort is of interest and will be investigated.

\section{Clinical Application}

Lead positioning is important for CRT response because anterolateral and lateral positions resulted in relatively better response compared with posterolateral and posterior positions. The LV lead may preferably be placed in such a region, accompanied by considerable electric delay, seen in high QLV/QRSd values. However, because QLV/QRSd (or RVp-LVs) is not capable of predicting the optimal electrode of a quadripolar lead after lead positioning in each individual patient, it should not be used for this purpose. The QLV/QRSd may, therefore, be used to select a vein for quadripolar LV lead placement, after which optimization of the pacing electrode should be dependent on functional assessment of CRT response. Because not all clinicians have access to PV-loop measurements, future studies on alternative and preferably noninvasive methods to optimize CRT response are of interest.

\section{Limitations}

Although the sample size is relatively large for an invasive study and conducted in multiple centers, it is limited by the number of patients included. The strict inclusion criteria also reduced the number of eligible patients and prolonged the time period of inclusion. Three patients with underestimation of baseline function were excluded because they showed PV loops with crossing lines. Some of the patients who were included in the final analysis experienced underestimation of baseline SW because of the fact that the shape of the loops was not rectangular but tailed, thereby reducing the area of the loop. This is a known phenomenon in conductance measurements for PV loops in patients with heart failure. Therefore, the absolute value of $\Delta \% \mathrm{SW}$ increase may be overestimated, but because of the repeated measurement design (ie, each patient serves as his own control), it is possible to compare different settings within each patient. Although the study methodology was complex and the distribution of patients over the 3 centers was uneven, baseline characteristics were comparable between centers, as well as the relationship between QLV/QRSd and $\triangle \%$ SW. Our methods may have a different result in patients with intraventricular conduction delay because optimization may have a bigger impact on patients with a less favorable substrate for CRT. The current protocol with various AV delays and pacing settings was time consuming. Therefore, the interventricular delay was fixed at an offset of 40 ms LV first because such an offset is favorable in most patients with CRT. ${ }^{16}$ Whether the acute hemodynamic response obtained in each patient correlates to an improved long-term prognosis is debatable. However, changes in $\mathrm{dP}^{\mathrm{d}} \mathrm{dt}_{\max }$ are unable 
to predict reverse remodeling, ${ }^{30}$ whereas changes in SW are associated with favorable volumetric response. ${ }^{20}$

\section{Conclusions}

There are large intraindividual variations in acute hemodynamic CRT response between electrodes of a quadripolar LV lead, indicating the benefit of patient-specific optimization. Although QLV/QRSd had a significant association with acute hemodynamic CRT response at group level, QLV/QRSd was not usable to predict the electrode of a quadripolar LV lead with the highest hemodynamic response for the individual patient. Therefore, optimization of the pacing configuration of CRT with a quadripolar LV lead should rely on functional assessment of cardiac function, instead of local electric delay.

\section{SOURCES OF FUNDING}

This study was conducted with an unrestricted research grant from St. Jude Medical (St. Paul, MN).

\section{DISCLOSURES}

Dr Meine has received research grants from Boston Scientific and St. Jude Medical. Dr Vernooy has received speaker fees and research grants from St. Jude Medical. Dr Prinzen has received research grants from Medtronic, Inc, Boston Scientific Corp, St. Jude Medical, LivaNova, Biosense Webster, and EBR Systems and is an advisor to Medtronic, Inc. The other authors report no conflicts.

\section{AFFILIATIONS}

From the Department of Cardiology, University Medical Center Utrecht, The Netherlands (W.M.v.E., M.J.C., P.A.D., M.M.); Department of Cardiology, Institute for Cardiovascular Research, VU University Medical Center, Amsterdam, The Netherlands (A.Z., A.C.v.R., C.P.A.); Department of Cardiology, Maastricht University Medical Center, The Netherlands (U.C.N., K.V.); and Department of Physiology, CARIM (Cardiovascular Research Institute Maastricht), Maastricht University, The Netherlands (U.C.N., F.W.P.).

\section{FOOTNOTES}

Received October 10, 2017; accepted January 17, 2018.

The Data Supplement is available at http://circep.ahajournals. org/lookup/suppl/doi:10.1161/CIRCEP.117.005912/-/DC1.

Circ Arrhythm Electrophysiol is available at http://circep. ahajournals.org.

\section{REFERENCES}

1. Russo AM, Stainback RF, Bailey SR, Epstein AE, Heidenreich PA, Jessup M, Kapa S, Kremers MS, Lindsay BD, Stevenson LW. ACCF/HRS/AHA ASE/HFSA/SCAI/SCCT/SCMR 2013 appropriate use criteria for implantable cardioverter-defibrillators and cardiac resynchronization therapy: a report of the American College of Cardiology Foundation appropriate use criteria task force, Heart Rhythm Society, American Heart Association,
American Society of Echocardiography, Heart Failure Society of America, Society for Cardiovascular Angiography and Interventions, Society of Cardiovascular Computed Tomography, and Society for Cardiovascular Magnetic Resonance. J Am Coll Cardiol. 2013;61:1318-1368. doi: 10.1016/j.jacc.2012.12.017.

2. Cleland JG, Daubert JC, Erdmann E, Freemantle N, Gras D, Kappenberger L, Tavazzi L; Cardiac Resynchronization-Heart Failure (CARE-HF) Study Investigators. The effect of cardiac resynchronization on morbidity and mortality in heart failure. N Eng/ J Med. 2005;352:1539-1549. doi: 10.1056/NEJMoa050496

3. Ghio S, Freemantle N, Scelsi L, Serio A, Magrini G, Pasotti M, Shankar A, Cleland JG, Tavazzi L. Long-term left ventricular reverse remodelling with cardiac resynchronization therapy: results from the CARE-HF trial. Eur J Heart Fail. 2009;11:480-488. doi: 10.1093/eurjhf/hfp034.

4. Wilkoff BL, Fauchier L, Stiles MK, Morillo CA, Al-Khatib SM, Almendral J, Aguinaga L, Berger RD, Cuesta A, Daubert JP, Dubner S, Ellenbogen KA, Estes NA III, Fenelon G, Garcia FC, Gasparini M, Haines DE, Healey JS, Hurtwitz JL, Keegan R, Kolb C, Kuck KH, Marinskis G, Martinelli M, Mcguire M, Molina LG, Okumura K, Proclemer A, Russo AM, Singh JP, Swerdlow CD, Teo WS, Uribe W, Viskin S, Wang CC, Zhang S; Document Reviewers. 2015 HRS/EHRA/APHRS/SOLAECE expert consensus statement on optimal implantable cardioverter-defibrillator programming and testing. Europace. 2016;18:159-183. doi: 10.1093/europace/euv411.

5. Khan FZ, Virdee MS, Palmer CR, Pugh PJ, O'Halloran D, Elsik M, Read PA, Begley D, Fynn SP, Dutka DP. Targeted left ventricular lead placement to guide cardiac resynchronization therapy: the TARGET study: a randomized, controlled trial. J Am Coll Cardiol. 2012;59:1509-1518. doi: 10.1016/j.jacc.2011.12.030.

6. Abu Daya H, Alam MB, Adelstein E, Schwartzman D, Jain S, Marek J, Gorcsan J, Saba S. Echocardiography-guided left ventricular lead placement for cardiac resynchronization therapy in ischemic vs nonischemic cardiomyopathy patients. Heart Rhythm. 2014;11:614-619. doi: 10.1016/j.hrthm.2014.01.023.

7. Bogaard MD, Doevendans PA, Leenders GE, Loh P, Hauer RN, van Wessel $\mathrm{H}$, Meine M. Can optimization of pacing settings compensate for a nonoptimal left ventricular pacing site? Europace. 2010;12:1262-1269. doi: 10.1093/europace/euq167.

8. van Everdingen WM, Cramer MJ, Doevendans PA, Meine M. Quadripolar leads in cardiac resynchronization therapy. J Am Coll Cardiol EP. 2015;1:225-237.

9. Pappone C, Ćalović Ž, Vicedomini G, Cuko A, McSpadden LC, Ryu K, Romano E, Saviano M, Baldi M, Pappone A, Ciaccio C, Giannelli L, lonescu B, Petretta A, Vitale R, Fundaliotis A, Tavazzi L, Santinelli V. Multipoint left ventricular pacing improves acute hemodynamic response assessed with pressure-volume loops in cardiac resynchronization therapy patients. Heart Rhythm. 2014;11:394-401. doi: 10.1016/j.hrthm.2013.11.023.

10. Thibault B, Dubuc M, Khairy P, Guerra PG, Macle L, Rivard L, Roy D, Talajic M, Karst E, Ryu K, Paiement P, Farazi TG. Acute haemodynamic comparison of multisite and biventricular pacing with a quadripolar left ventricular lead. Europace. 2013;15:984-991. doi: 10.1093/europace/eus435.

11. Gold MR, Birgersdotter-Green U, Singh JP, Ellenbogen KA, Yu Y, Meyer $T E$, Seth M, Tchou PJ. The relationship between ventricular electrical delay and left ventricular remodelling with cardiac resynchronization therapy. Eur Heart J. 2011;32:2516-2524. doi: 10.1093/eurheartj/ehr329.

12. Singh JP, Fan D, Heist EK, Alabiad CR, Taub C, Reddy V, Mansour M, Picard MH, Ruskin JN, Mela T. Left ventricular lead electrical delay predicts response to cardiac resynchronization therapy. Heart Rhythm. 2006;3:1285-1292. doi: 10.1016/j.hrthm.2006.07.034.

13. Singh JP, Klein HU, Huang DT, Reek $S$, Kuniss $M$, Quesada A, Barsheshet A, Cannom D, Goldenberg I, McNitt S, Daubert JP, Zareba W, Moss AJ. Left ventricular lead position and clinical outcome in the multicenter automatic defibrillator implantation trial-cardiac resynchronization therapy (MADIT-CRT) trial. Circulation. 2011;123:1159-1166. doi: 10.1161/CIRCULATIONAHA.110.000646.

14. Kronborg MB, Johansen JB, Riahi S, Petersen HH, Haarbo J, Jørgensen OD, Nielsen JC. An anterior left ventricular lead position is associated with increased mortality and non-response in cardiac resynchronization therapy. Int J Cardiol. 2016;222:157-162. doi: 10.1016/j.jijcard.2016.07.235.

15. Strauss DG, Selvester RH, Wagner GS. Defining left bundle branch block in the era of cardiac resynchronization therapy. Am J Cardiol. 2011;107:927934. doi: 10.1016/j.amjcard.2010.11.010. 
16. Bogaard MD, Meine M, Tuinenburg AE, Maskara B, Loh P, Doevendans PA. Cardiac resynchronization therapy beyond nominal settings: who needs individual programming of the atrioventricular and interventricular delay? Europace. 2012;14:1746-1753. doi: 10.1093/europace/eus170.

17. Sohaib SM, Whinnett ZI, Ellenbogen KA, Stellbrink C, Quinn TA, Bogaard MD, Bordachar P, van Gelder BM, van Geldorp IE, Linde C, Meine M, Prinzen FW, Turcott RG, Spotnitz HM, Wichterle D, Francis DP. Cardiac resynchronisation therapy optimisation strategies: systematic classification, detailed analysis, minimum standards and a roadmap for development and testing. Int J Cardiol. 2013;170:118-131.

18. Helm RH, Byrne M, Helm PA, Daya SK, Osman NF, Tunin R, Halperin HR, Berger RD, Kass DA, Lardo AC. Three-dimensional mapping of optimal left ventricular pacing site for cardiac resynchronization. Circulation. 2007;115:953-961. doi: 10.1161/CIRCULATIONAHA.106.643718.

19. Zanon F, Baracca E, Pastore G, Fraccaro C, Roncon L, Aggio S, Noventa $F$, Mazza A, Prinzen F. Determination of the longest intrapatient left ventricular electrical delay may predict acute hemodynamic improvement in patients after cardiac resynchronization therapy. Circ Arrhythm Electrophysiol. 2014;7:377-383. doi: 10.1161/CIRCEP.113.000850.

20. de Roest GJ, Allaart CP, Kleijn SA, Delnoy PP, Wu L, Hendriks ML, Bronzwaer $J G$, van Rossum AC, de Cock CC. Prediction of long-term outcome of cardiac resynchronization therapy by acute pressure-volume loop measurements. Eur J Heart Fail. 2013;15:299-307. doi: 10.1093/eurjhf/hfs190.

21. Sterliński M, Sokal A, Lenarczyk R, Van Heuverswyn F, Rinaldi CA, Vanderheyden M, Khalameizer V, Francis D, Heynens J, Stegemann B, Cornelussen $R$. In heart failure patients with left bundle branch block single lead Multispot left ventricular pacing does not improve acute hemodynamic response to conventional biventricular pacing. A multicenter prospective, interventional, non-randomized study. PLoS One. 2016;11:e0154024. doi: 10.1371/journal.pone.0154024.

22. Mafi Rad M, Blaauw Y, Dinh T, Pison L, Crijns HJ, Prinzen FW, Vernooy K Different regions of latest electrical activation during left bundle-branch block and right ventricular pacing in cardiac resynchronization therapy patients determined by coronary venous electro-anatomic mapping. Eur J Heart Fail. 2014;16:1214-1222. doi: 10.1002/ejhf.178.

23. Pluijmert M, Bovendeerd PH, Lumens J, Vernooy K, Prinzen FW, Delhaas T. New insights from a computational model on the relation between pac- ing site and CRT response. Europace. 2016;18(suppl 4):iv94-iv103. doi: 10.1093/europace/euw355.

24. Saxon LA, Olshansky B, Volosin K, Steinberg JS, Lee BK, Tomassoni G, Guarnieri T, Rao A, Yong P, Galle E, Leigh J, Ecklund F, Bristow MR. Influence of left ventricular lead location on outcomes in the COMPANION study. J Cardiovasc Electrophysiol. 2009;20:764-768. doi: 10.1111/j. 1540-8167.2009.01444.x.

25. Thébault C, Donal E, Meunier C, Gervais R, Gerritse B, Gold MR, Abraham WT, Linde C, Daubert JC; REVERSE Study Group. Sites of left and right ventricular lead implantation and response to cardiac resynchronization therapy observations from the REVERSE trial. Eur Heart J. 2012;33:26622671. doi: 10.1093/eurhearti/ehr505.

26. de Roest GJ, Wu L, de Cock CC, Delnoy PP, Hendriks ML, van Rossum AC, Allaart CP. Bifocal left ventricular stimulation or the optimal left ventricular stimulation site in cardiac resynchronization therapy: a pressure-volume loop study. Europace. 2016;18:1030-1037. doi: 10.1093/europace/euv280.

27. Shetty AK, Duckett SG, Ma YL, Kapetanakis S, Ginks M, Bostock J, Carr-White G, Rhode K, Razavi R, Rinaldi CA. The acute hemodynamic response to LV pacing within individual branches of the coronary sinus using a quadripolar lead. Pacing Clin Electrophysiol. 2012;35:196-203. doi: 10.1111/j.1540-8159.2011.03268.x.

28. Pappone C, Ćalović Ž, Vicedomini G, Cuko A, McSpadden LC, Ryu K, Jordan CD, Romano E, Baldi M, Saviano M, Pappone A, Vitale R, Catalano C, Ciaccio C, Giannelli L, lonescu B, Petretta A, Fragakis N, Fundaliotis A, Tavazzi L, Santinelli V. Improving cardiac resynchronization therapy response with multipoint left ventricular pacing: twelve-month follow-up study. Heart Rhythm. 2015;12:1250-1258. doi: 10.1016/j.hrthm.2015.02.008.

29. Zanon F, Marcantoni L, Baracca E, Pastore G, Lanza D, Fraccaro C, Picariello C, Conte L, Aggio S, Roncon L, Pacetta D, Badie N, Noventa F, Prinzen FW. Optimization of left ventricular pacing site plus multipoint pacing improves remodeling and clinical response to cardiac resynchronization therapy at 1 year. Heart Rhythm. 2016;13:1644-1651. doi: 10.1016/j.hrthm.2016.05.015.

30. Bogaard MD, Houthuizen P, Bracke FA, Doevendans PA, Prinzen FW, Meine $\mathrm{M}$, van Gelder BM. Baseline left ventricular dP/dtmax rather than the acute improvement in $\mathrm{dP} / \mathrm{dtmax}$ predicts clinical outcome in patients with cardiac resynchronization therapy. Eur J Heart Fail. 2011;13:1126-1132. doi: 10.1093/eurjhf/hfr094. 